\title{
ИССЛЕДОВАНИЕ СВЯЗИ ТИПОВ ШКОЛЬНОЙ ДЕЗАДАПТАЦИИ ПОДРОСТКОВ С АКЦЕНТУАЦИЯМИ ХАРАКТЕРА
}

\author{
Е. С. Кузьмина \\ Московский гуманитарный университет
}

Аннотация: В статье приведено описание исследования эмоционально-личностной сферы подростков, установлена связь между акцентуациями характера подростка и различными типами школьной дезадаптации.

Ключевые слова: школьная адаптация; школьная дезадаптация; акцентуация характера; подросток; школьник

\section{RESEARCH INTO THE TYPES OF SCHOOL DISADAPTATION OF TEENAGERS WITH CHARACTER ACCENTUATION}

\author{
E. S. Kuzmina \\ Moscow University for the Humanities
}

\begin{abstract}
The article provides a description of a research into the emotional and personal sphere of teenagers, establishes a connection between a teenager's character accentuations and various types of school disadaptation.

Keywords: school adaptation; school disadaptation; character accentuation; teenager; school child
\end{abstract}

Современное общество меняется быстрыми темпами. Проводятся всевозможные реформы, призванные модернизировать старые социальные институты, с целью улучшения их функционирования. Модернизация в первую очередь происходит за счет внедрения новых цифровых технологий во все сферы нашей жизни. Это преобразования не могло не затронуть и систему образования. Реформы коснулись как технических средств ведения занятий, так и методик их проведения. Данные изменения были созданы с целью повышения качества образования современных школьников. Но несмотря на все новые образовательные технологии, проблема школьной дезадаптации остается незыблемой в современных образовательных организациях (Вострокнутов, 2015; Карбанович, 2012; Молодцова, 2013: Электр. ресурс; 
Самохвалова, 2014). В каждом классе есть учащиеся, которые неуспешны в учебной деятельности, проявляют агрессию по отношению к сверстникам и педагогам, совершают поступки, асоциального характера. Каждый педагог, каждый человек, работающий с такими подростками, хочет знать алгоритм работы с данным контингентом. Чтобы корректировать поведение подростка, необходимо представлять, что является причиной того или иного вида поведения, которое может быть обусловлено как внешними, так и внутренними факторами.

В своей работе мы описываем исследование, которое было проведено среди учащихся 9-11 классов ГБОУ школа № 1574 г. Москва с целью установить связь между формой проявления школьной дезадаптации и личностными особенностями подростков, такими как акцентуации характера, темперамент. Гипотеза нашего исследования заключается в следующем: мы полагаем, что форма проявления школьной дезадаптации имеет непосредственную связь с акцентуациями характера.

Чтобы выявить подростков с различными типами школьной дезадаптации, был проведен ряд диагностических методик, таких как методика исследования уровня мотивации Лускановой, шкала школьной тревожности Кондаша, исследование самооценки подростка, анкета «мое отношение к учению», была использована карта Скотта, и характеристики от учителей предметников, а также был проведен анализ успеваемости.

Школьная дезадапатация имеет три типа: когнитивный, эмоционально-оценочный и поведенческий (Молодцова, 2013: Электр. ресурс).

Когнитивный тип школьной дезадаптации самый явные среди прочих, он проявляется в хронической неуспеваемости школьника по ряду предметов, в отсутствии у учащегося сформированных навыков и умений.

Эмоционально-оценочная дезадаптация проявляется как негативное отношение к отдельным предметам, учителю или процессу обучения в целом.

Поведенческая дезадаптация представляется нам как совокупность поступков, противоречащих правилам внутреннего распорядка образовательной организации, в систематических нарушениях дисциплины, прогулах и в крайних случаях, в школьном вандализме.

Школьная дезадаптация может проявляться как совокупность всех трех типов, или быть представлена одним из них.

Итак, исходя из результатов проведенных диагностических методик, мы выявили то, что подростки, с низкой самооценкой, высоким уровнем школьной тревожности, третьим уровнем мотивации, с низкими показателями по шкалам «понимаю объяснения учителя», «знаю этот предмет», проявляют только когнитивный тип школьной дезадапатции. Учителя ха- 
Научные труды Московского гуманитарного университета 2019 № 4

рактеризуют таких подростков как застенчивых, робких, «незаметных», тихих, пассивных, чувствительных. В анкете «мое отношение к учению», такие подростки демонстрируют высокие балы по позициям «люблю этот предмет», «доволен отношением учителя», что может говорить об отсутствии эмоционально-оценочной дезадаптации.

К учащимся, которые проявляют как когнитивный, так и эмоционально-оценочный компонент школьной дезадаптации, относятся подростки с заниженной или завышенной самооценкой, уровень тревожности у них или очень высокий, или они демонстрируют «чрезмерное спокойствие», уровень мотивации у этой группы ребят находиться в крайней границе нормы, то есть им соответствует третий и иногда четвертый уровни мотивации. Подростки с когнитивной и эмоционально-оценочной дезадаптацией поставили достаточно низкие баллы по шкалам «доволен отношением учителя», «люблю этот предмет», особенно по тем дисциплинам, по которым их оценки находятся в диапазоне между «неудовлетворительно» и « удовлетворительно».

Когнитивный и поведенческие типы школьной дезадаптации также соответствуют подросткам с неадекватной самооценкой, она у них либо очень низкая, либо высокая. Уровень тревожности в основном находится ниже возрастной нормы, то есть такие подростки прибывают в состоянии «чрезмерного спокойствия», мотивация у них варьируется между третьим и четвертым уровнями. В анкете «мое отношение к учению», подростки демонстрируют средние баллы по всем позициям, иными словами относятся ко всей школьной ситуации индифферентно.

Все три типа школьной дезадапатции характерны для подростков с низкой самооценкой, очень низким уровнем мотивации (пятый уровень), состоянием «чрезмерного спокойствия». По результатам анкеты «мое отношение к учению», такие подростки недовольны отношением учителей, не любят различные дисциплины, не понимают их. Учителя характеризуют таких учащихся, как вспыльчивых, агрессивных, слабых, склонных к асоциальным поступкам.

Исходя из полученных данных были составлены таблица № 1 и рис. 1. Таблица 1. Соотношение типов школьной дезадапатции, в \%.

\begin{tabular}{|c|c|}
\hline Компоненты дезадаптации & $\begin{array}{c}\text { Процент } \\
\text { контингента }\end{array}$ \\
\hline Когнитивный & 10,53 \\
\hline Когнитивный, эмоционально-оценочный & 36,84 \\
\hline Когнитивный, поведенческий & 47,37 \\
\hline Когнитивный, эмоционально-оценочный, поведенческий & 5,26 \\
\hline
\end{tabular}




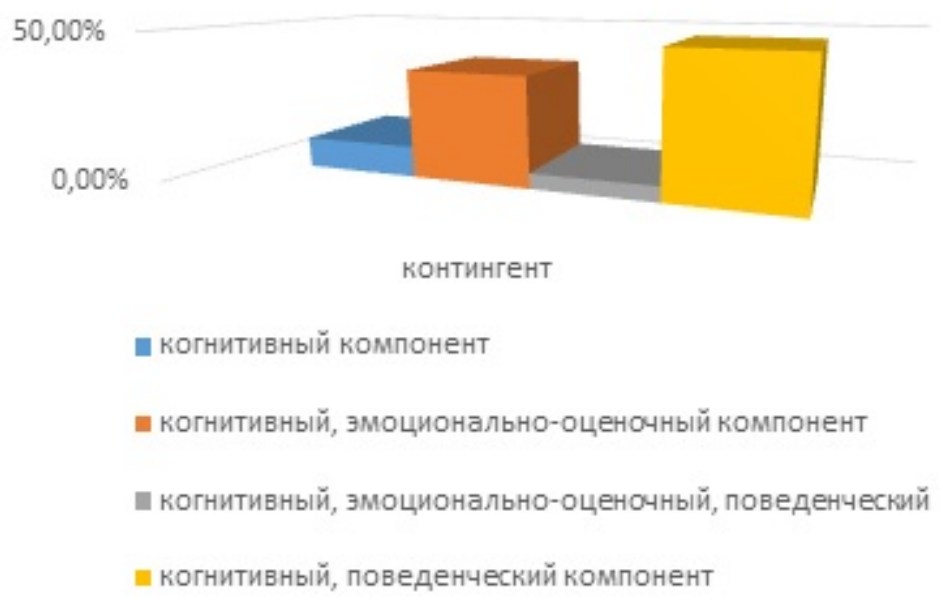

Рисунок 1. Соотношение типов школьной дезадаптации.

Мы видим, что почти половина подростков, которые попали в выборку, проявляют когнитивный и поведенческий тип школьной дезадаптации. Такие учащиеся составляют $47,37 \%$ от общего контингента испытуемых.

Когнитивный и эмоционально-оценочный компоненты школьной дезадаптации проявляются у 36,84\% учащихся 9-11 классов. Только когнитивный компонент школьной дезадаптации, который мы рассматриваем как хроническую неуспеваемость, присущ 10,53\% подростков. Все три типа школьной дезадаптации характеры для 5,26\%. Анализируя результаты, можно сделать вывод, что некоторые общие характеристики имеют место для различных типов школьной дезадаптации, и данные диагностики не могут дать полной картины, о том, что стало причиной той или иной формы неправильно протекающей адаптации. В связи с этим, было принято решение о поиске причин дезадапатции в личностных особенностях подростков. Исходя из вышеприведенного предположения о том, что форма школьной дезадаптации имеет связь с акцентуациями характера, было проведено исследование эмоционально-личностной сферы подростков по методике Шмишека и Айзенка.

Акцентуации характера можно рассматривать как временные изменения характера индивида в процессе его взросления (Бадиев, 2015). Акцентуации в психологии рассматриваются как крайний вариант нормы (Зинченко, Мещеряков, 2008). Иными словами, акцентуации являются чрезмерным усилением определенных черт характера.

Тестирование проводилось по адаптированной методике Шмишека (адаптация Крук). В данной методике выделены следующие типы акцентуаций: гипертимный, циклоидный, лабильный, сензитивный, психастенический, шизоидный, эпиллептоидный, истероидный, неустойчивый. 

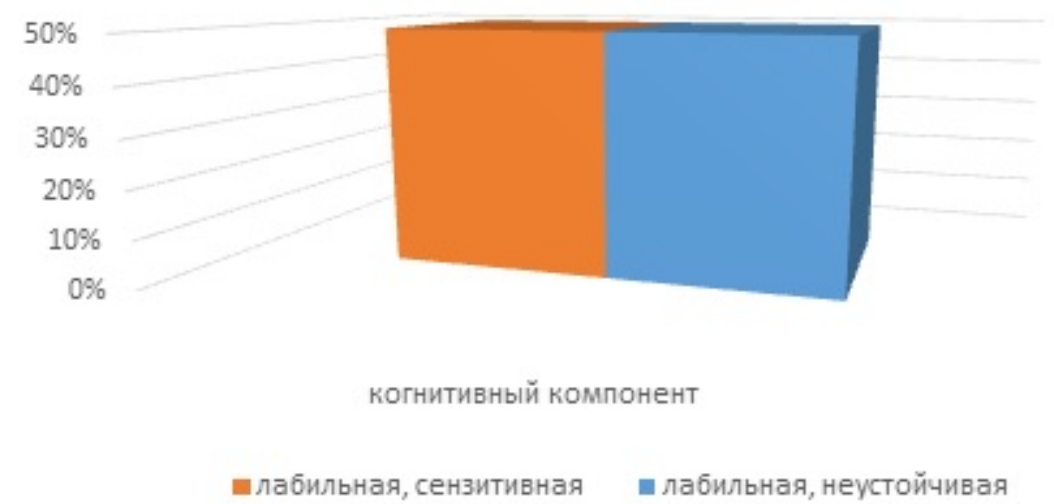

Рисунок 2. Связь когнитивного типа школьной дезадаптации с акцентуациями характера.

Анализируя данные диагностики можно сделать вывод о том, что учащиеся группы риска, у которых наблюдается только когнитивный компонент дезадаптации, имеют акцентуации лабильную и неустойчивую акцентуацию или в вариации лабильная плюс сензитивная, выраженные в равной мере. 50\% испытуемых имеют лабильную и неустойчивую акцентуацию и $50 \%$ имеют лабильную и сензитивную акцентуацию (рис. 2).

Для лабильных подростков характерна частая смена настроения, порой кажущаяся абсолютно не мотивированной (Личко, 1982). Такие перепады могут происходить несколько раз в день. Подростки с данной акцентуацией очень чувствительны к чужому мнению, они чрезмерно ранимы и обидчивы. Реакция эмансипации у таких подростков полностью зависит от их настроения. Компании обычно не постоянны и часто меняются. Для лабильного типа не свойственны грубые нарушения поведения. Лабильным подросткам свойственны депрессии, неврозы, аффективные реакции, которые могут быть спровоцированы даже неумелой шуткой в их адрес, грубостью или неудачей. Неустойчивая акцентуация, которая также встречается здесь, обуславливает безволие по отношению к учебной деятельности, стремление наслаждаться жизнью и получать удовольствие.

При сочетании акцентуации лабильного и сензитивного типа, мы имеем дело с подростком, который помимо частой смены настроения, повышенной ранимости и обидчивости, постоянно испытывают чувство собственной неполноценности. Порой это чувство может компенсироваться внешней бравадой.

Сензитивный тип акцентуации присущ подросткам, которые стараются отгородится от сверстников, им комфортнее наедине с собой, но учитывая наличие акцентуации лабильного типа можно сказать, что реакции группирования и эмансипации подвержены перепадам настроения. 
Когнитивный и эмоционально-оценочный тип школьной дезадаптации, присущ подросткам со следующими акцентуациями характера: Циклоидной, лабильной, сензитивной, неустойчивой (рис. 3).

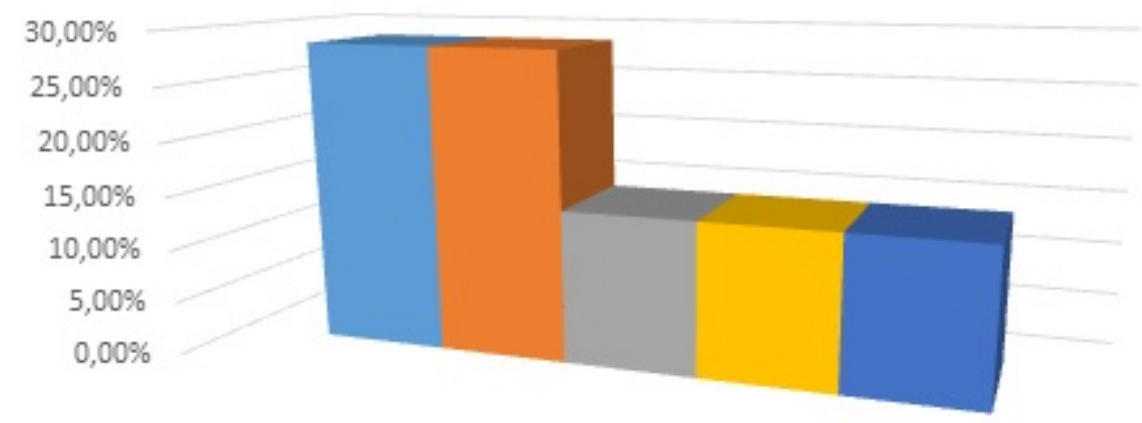

контенгент

плабильная, неустойчивая шензитивная, неустойчивая

шциклоидная, лабильная, неустойчивая шинклоидная, неустойчивая

плабильная, сензитивная, неустойчивая

Рисунок 3. Связь когнитивного и эмоционально-оценочного типа школьной дезадаптации с акцентуациями характера.

Перед нами подростки, которые сочетают акцентуации по следующим типам: Лабильный и неустойчивый, циклоидый и неустойчивый, сензитивный и неустойчивы, циклоидный, лабильный и неустойчивый, лабильный, сензитивный и неустойчивый.

Общая акцентуация для всех подростков с данными типами дезадапатции, неустойчивая.

Циклоидный плюс неустойчивый тип. Для подростков данного типа, как и для лабильный подростков, характерна смена настроения, причем оно может меняться от самого радужного, до глубокой депрессии. В момент подъема настроения, такие подростки активы, общительны, неусидчивы, напоминают по своему поведению подростков с гипертимной акцентуацией. Реакции эмансипации также проявляются в фазу хорошего настроения. В момент спада, такие подростки ощущают свою неполноценность, они становятся неуверенны в себе, стараются оставаться наедине с собой. Неустойчивая акцентуация проявляет себя в тяге к развлечениям, которые не требуют от подростка волевых усилий.

Сочетание сензитивной и неустойчивой акцентуации дает нам подростка, которые испытывает чувство собственной неполноценности, но скрывает его под внешней бравадой, очень тяжело переносит неудачи, а 
также, он может проявлять безволие по отношению к учебной активности.

Обобщая характеристики различных акцентуаций, которые свойственны подросткам с когнитивной и эмоционально-оценочной школьной дезадаптации, можно заключить следующее: Для всех этих подростков характерна чувствительность, они глубоко переживают свои неудачи, могут обижаться по пустяковым поводам, привязаны к личностно-значимым взрослым, тяжело переносят смену обстановки и коллектива. Но также, каждый из них стремится к получению удовольствия без приложения усилий, отсутствие или слабость волевого контроля проявляется в учебной и социальной деятельности.

Когнитивный и поведенческий тип школьной дезадаптации в основном присутствует у подростков с гипертимной и неустойчивой акцентуациями (рис. 4).

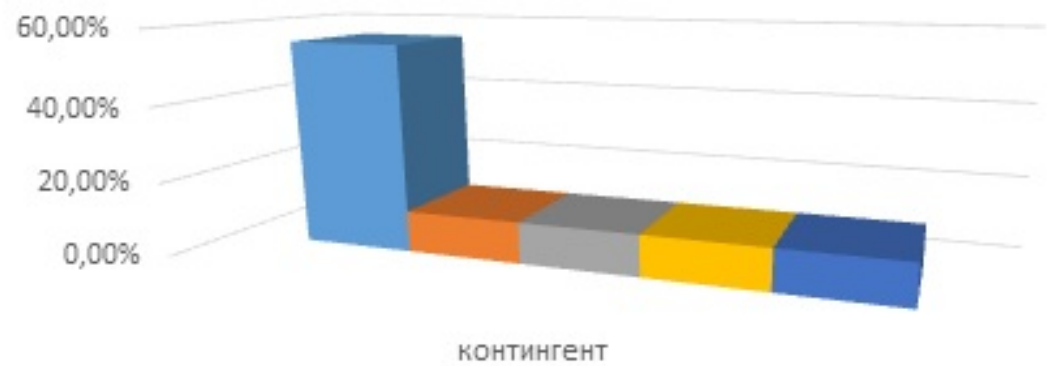

контингент

п гипертимная,неустойчивая пеустойчивая

ш гипертимная, циклоидная, неустойчивая циклоидная, неустойчивая

пабильная, неустойчивая

Рисунок 4. Связь когнитивного и поведенческого компонента школьной дезадаптации с акцентуациями характера.

Когнитивный и поведенческий компоненты, проявляются в систематических нарушениях поведения. Как видно из диаграммы видно, что большая часть подростков, которые демонстрируют данные компоненты школьной дезадаптации, имеют гипертимную и неустойчивую акцентуации.

Гипертимная акцентуация характера у подростков характеризуется в основном хорошим приподнятым настроением, склонностью к озорству, подвижностью. Факторами, которые провоцируют дезадаптацию, можно отнести ограничение возможностей контактировать со сверстниками, жесткий контроль, эмоциональное отвержение.

Дезадаптация проявляется в виде неусидчивости, отвлекаемости, прогулы, конфликты, недисциплинированности. 
Неустойчивая акцентуация проявляется в склонности подростков к развлечениям, которые не требуют волевых усилий. Проявляют безволие по отношению к учебной деятельности.

Анализируя данные, полученные в результате исследования, можно сделать вывод, что школьная дезадаптация проявляется в основном у подростков в неустойчивой акцентуацией характера, порождая когнитивный компонент школьной дезадаптации. Данный компонент развивается и усугубляется у подростков с лабильной и сензитивной акцентуациями, в силу их особенностей. Когнитивный и эмоционально оценочный компоненты школьной дезадаптации, проявляются у подростков с акцентуациями, характеризующими их эмоциональную неустойчивость, то есть лабильных, сензитивных, циклоидных. Когнитивный и поведенческий компонент характерен для учащихся с гипертимной акцентуацией.

Таким образом, можно заключить, что типы школьной дезадаптации имеют связь с акцентуациями характера.

\section{СПИСОК ЛИТЕРАТУРЫ}

Бадиев, И. В. (2015) Типология акцентуаций характера у подростков // Вестник Бурятского государственного университета. № 5. С. 60-65.

Вострокнутов, Н. В. (1995) Школьная дезадаптация: ключевые проблемы диагностики и реабилитации // Школьная дезадаптация: Эмоциональные и стрессовые расстройства у детей и подростков. Материалы Всероссийской научно-практической конференции 25-27 октября 1995 г. М. C. 8-11.

Карбанович, О. В. (2012) Психолого-педагогические условия преодоления школьной дезадаптации // Вестник Брянского государственного университета. № 2. С. 74-79.

Личко, А. Е. (1982) Психопатии и акцентуации характера у подростков // Психология индивидуальных различий. Тексты / под ред. Ю. Б. Гиппенрейтер, В. Я. Романова. М. : Изд-во МГУ. С. 288-318.

Зинченко, В. П., Мещеряков, Б. Г. (2008) Большой психологический словарь. 4-е изд. М.: АСТ-Москва.

Молодцова, Т. Д. (2013) Основные виды и типы подростковой дезадаптации [Электронный ресурс] // Концепт. № 5. URL: http://e-koncept. ru/2013/13099.htm (дата обращения: 14.08.2019).

Самохвалова, А. Г. (2013) Акцентуации характера фактор затрудненного общения подростков // Вестник Костромского государственного университета. Т. 19. № 4. С. 47-53. 
Кузьмина Екатерина Сергеевна - магистрант кафедры педагогики и психологии высшей школы Московского гуманитарного университета. Адрес: 111395, Россия, г. Москва, ул. Юности, д. 5 . Тел.: +7 (499) 374-74-59. Эл. адрес: kusuni4@yandex.ru. Научный руководитель — канд. пед. н., доцент А. А. Фортунатов.

Kuzmina Ekaterina Sergeyevna, Graduate Student, Department of Pedagogy and Psychology of Higher Education, Moscow University for the Humanities. Postal address: 5, Yunosti St., Moscow, Russian Federation, 111395. Tel.: +7 (499) 374- 74-59. E-mail: kusuni4@yandex.ru. Scientific Adviser - A. A. Fortunatov, Candidate of Pedagogy, Associate Professor.

\section{Для цитирования:}

Кузьмина Е. С. Исследование связи типов школьной дезадаптации подростков с акцептуациями характера [Электронный ресурс] // Научные труды Московского гуманитарного университета. 2019. № 4. URL: http://journals.mosgu.ru/trudy/article/view/1015 (дата обращения: дд.мм.гг.). DOI: 10.17805/trudy.2019.4.7 